\title{
TELETRABALHO E O CONTROLE DA PRODUTIVIDADE NA FASE PROCESSUAL DA EXECUÇÃO TRABALHISTA
}

\section{ARTIGO ORIGINAL}

BATISTA, Gabriel Muniz ${ }^{1}$

CUNHA, Doralice Orrigo da ${ }^{2}$

FINAMOR, Ana Lígia ${ }^{3}$

BATISTA, Gabriel Muniz. CUNHA, Doralice Orrigo da. FINAMOR, Ana Lígia. Teletrabalho e o controle da produtividade na fase processual da execução trabalhista. Revista Científica Multidisciplinar Núcleo do Conhecimento. Ano 05, Ed. 12, Vol. 15, pp. 197-213. Dezembro de 2020. ISSN: 2448-0959, Link de acesso: https://www.nucleodoconhecimento.com.br/administracao/fase-processual

\section{RESUMO}

A questão do controle da produtividade intelectual é desafiadora, porque é necessário tornar tangível algo que tenha várias dimensões. O objetivo deste trabalho foi contribuir cientificamente para a criação de um sistema de controle mais assertivo para a produtividade da fase processual da execução trabalhista. Para tanto, esta pesquisa aplicada utilizou-se do procedimento descritivo nas formas de estudos descritivos e de pesquisas de opinião. Revelou-se que além da produção de mão de obra, outras variáveis, como qualidade, tempo e flexibilidade, devem ser consideradas, tanto como ferramentas para o controle da produtividade, como para estratégia competitiva.

\footnotetext{
${ }^{1}$ MBA em Gestão de Pessoas e Liderança de Pós-Graduação lato sensu, nível de Especialização.

2 Orientadora. Doutorado em Ciências da atividade física e dos esportes.

${ }^{3}$ Coordenadora. Doutorado em Ciências da Atividade Física e do Esporte.
} 
Palavras-Chave: produtividade intelectual, estratégia competitiva, controle.

\section{INTRODUÇÃO}

Muitas empresas foram obrigadas a iniciarem ou a intensificarem o regime de teletrabalho para seus funcionários, devido à pandemia de COVID-19, doença causada pelo novo Coronavírus - Sars-Cov-2, declarada pela Organização Mundial de Saúde em 11/03/2020.

Com os órgãos do Poder Judiciário não foi diferente, eles já possuíam uma legislação a respeito, a qual autorizava o trabalho nesse regime, mas até então o número de servidores que atuavam nele era substancialmente menor e desde então vários deles estão funcionando por teletrabalho.

Um dos normativos nesse sentido é o Ato Regulamentar GP no 10, de 30 de julho de 2018, que regulamenta a modalidade de teletrabalho no âmbito do Egrégio Tribunal

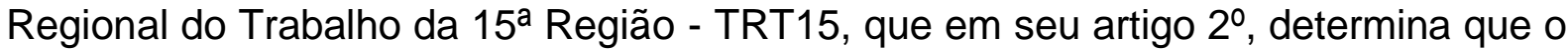
teletrabalho será restrito às atribuições nas quais seja possível a mensuração objetiva do seu desempenho.

Daí então a preocupação com essa mensuração surge, seria possível mensurar objetivamente a produtividade de um trabalho intelectual? E como evitar desvios que poderiam atrasar o processo em mais de uma década, em favor da produtividade diária?

Ademais, para Castro (2014), além de promover a cidadania e servir ao interesse público, o Estado deve empenhar-se no oferecimento de serviços com a melhor qualidade possível, segundo os termos da lei e do accountability. Ou seja, mediante uma gestão responsável, ética, transparente, inclusive sob o crivo de controle social.

Nesse contexto, mais do que nunca, é necessário encontrar formas de controle de produtividade e desempenho de cada unidade do Poder Judiciário, com regras de mensuração objetivas, claras e compatíveis com os trabalhos. E muitos esforços vêm sendo realizados pelos órgãos do Poder Judiciário neste sentido. 
Um exemplo desse compromisso é o do TRT15, que permitiu que sua produtividade estivesse disponível em seu site, que apresentou um número de sentenças de 151.543, de decisões de 169.007, de despachos de 453.699, de atos cumpridos por servidores de 7.535.491 e de valores liberados para combate ao Coronavírus de $\mathrm{R} \$$ 22.739.702,58.

Complementarmente, o controle de produtividade na fase de execução é uma das tarefas mais desafiadoras para seu gestor, pelas características distintas dessa fase em relação às fases de conhecimento e de liquidação, sendo que esta última, não necessariamente seria uma fase autônoma, e sim preparatória da execução.

E para entendermos melhor essa realidade, primeiramente devemos saber que para iniciarmos uma execução, precisamos de um título executivo judicial ou extrajudicial. Esses títulos estão descritos no artigo 876 da Consolidação das Leis Trabalhistas CLT, e para doutrina trabalhista majoritária seu rol é taxativo, isso significa que os títulos executivos trabalhistas existentes estão neste artigo.

São eles: as decisões passadas em julgado ou das quais não tenha havido recurso com efeito suspensivo; os acordos, quando não cumpridos; os termos de ajuste de conduta firmados perante o Ministério Público do Trabalho e os termos de conciliação firmados perante as Comissões de Conciliação Prévia.

Nessa fase visa-se a concretização da Justiça, porque é nela que, na maioria das vezes, o credor recebe de fato a prestação jurisdicional. Podemos citar como exemplo, não só o cumprimento de uma obrigação de pagar, seja espontaneamente, seja por meio de expropriação de bens, mas também, o cumprimento de outras obrigações, como ativação de um plano de saúde, reintegração ao serviço, anotação de Carteira de Trabalho e Previdência Social - CTPS, expedição de alvarás para saque do FGTS e entrada no Seguro Desemprego.

Isso mostra a importância dessa fase, que muitas vezes é negligenciada pelos operadores do Direito, pois como apresentado, é nessa fase que há grande parte da materialização e cumprimento da Justiça ao caso concreto. Mas não é só isso, a 
gestão eficiente dessa fase, pode trazer resultados positivos também em outras áreas, como o aumento de conciliações homologadas, dos pagamentos voluntários e do desenvolvimento econômico regional.

E esse fato não passou despercebido por parte de empresários devedores trabalhistas que apoiaram a Reforma Trabalhista de 2017, porque com a nova redação do art. 878 da CLT, a execução deverá ser promovida pelas partes, como regra. Isso pode causar diversas consequências negativas a administração dos processos nessa fase.

A título de exemplo, podemos citar a possibilidade de processos semelhantes resultarem em prazos e procedimentos totalmente distintos em seus deslindes, a depender do pedido ou da inércia do advogado do exequente. O que de certa forma tiraria um pouco da responsabilidade do eficientismo do órgão público e o transferiria aos advogados. Mas na prática, como a cobrança de eficiência permanece sobre os Juízes e consequentemente sobre seus auxiliares, desde a vigência dessa alteração, manobras jurídicas são realizadas por muitos magistrados e auxiliares para evitar esse problema.

Somando-se a essa mudança legislativa, os executados fazem diversos cálculos para não pagarem suas dívidas trabalhistas, como: não possuírem bens em seu nome ou de sua empresa; os juros e taxas de correção monetária dos valores executados serem menores que os de mercado; a demora do processo possibilita a dilapidação de bens e é possível que os sócios abram outra empresa, mesmo que possuam seus nomes no Banco Nacional de Devedores Trabalhistas - BNDT.

As artimanhas dos executados são várias para não pagarem, e exigem uma certa habilidade do servidor no preparo das minutas de decisão, que muitas vezes vão além do popular "feijão com arroz". Estamos falando de uma fase que poderia ser comparada a uma investigação policial, para a Justiça Criminal, por ser também uma fase investigativa. Contudo, diferentemente desta, a execução trabalhista é a última fase processual e, como regra, é direcionada à busca de patrimônio do devedor. 
Diante de tanta relevância do trabalho e de suas especificidades, muitas vezes os servidores são levados a raciocínios equivocados, que podem levar o processo a um caminho de "espaço tempo" praticamente indefinido. Dessa forma, há a possibilidade de que muitos dos processos trabalhados, fiquem por mais de dez anos, sendo movimentado num "labirinto" sem fim. E com a possibilidade de que os servidores responsáveis pelas minutas que levaram esses processos a esse caminho, os tivessem computados em seus relatórios de produtividade diária positivamente.

Para complicar a situação, o fato de que dentro do campo jurídico, suas minutas de decisão poderiam ser aceitáveis, desde que estivessem dentro dos parâmetros definidos pelo Magistrado e gestores para casos concretos semelhantes.

Mas, como evitar isso? Imagine se as diretrizes e margens de discricionariedade fossem mais objetivas e bem trabalhadas, e que o controle de produtividade conseguisse prever a porcentagem de colaboração daquela minuta, para alcançar a prestação jurisdicional a tempo de promover a pacificação social, que é a razão de ser do Poder Judiciário, ao invés do cômputo do simples número de processos movimentados. Evitando-se a movimentação de processos para um "limbo" processual.

Além disso, devemos também levar em conta a existência de fatores extraprocessuais que impactam na produtividade do servidor em teletrabalho, como internet, ergonomia dos móveis, equipamentos, iluminação, ambiente, ruídos sonoros, temperatura, motivação, condição psicológica, família, etc.

Um outro ponto importante é sobre a imposição de uma produtividade maior do trabalhador em teletrabalho do que em presencial. O que de acordo com a Advogada e Especialista em Direito e Processo do Trabalho Dra. Aimée Mastella Sampaio da Silva.

Não haveria razão de existir exigência de maior produtividade ao teletrabalho só porque é realizado em casa, permanecendo inconscientemente a mentalidade de que o trabalhador em sua residência trabalha menos, ainda que produza o mesmo em relação à produção em seu local do trabalho. Tal exigência tem o intuito de 
incentivo à produção, pelo conforto que a casa proporcionaria ao trabalhador, o que ocasionaria estímulo maior ao trabalho, mas afronta a igualdade e acarreta certa discriminação. (SILVA, 2015, p. 5).

Superada essa discussão, será preciso descrever as principais atividades a serem realizadas nas tarefas da fase de execução, buscar uma padronização possível para cada uma das respostas a serem dadas pelo Juízo e encontrar um tempo estimado para cada uma delas, conseguindo assim um inventário delas, com pesos de acordo com a dificuldade e tempo para suas realizações, e também incluir, formas de medir a realização do trabalho de maneira incompleta ou não conforme, como fatores de redução da produtividade.

E para esse fim, o Fluxo Nacional da Justiça do Trabalho é uma importante ferramenta, que de forma colaborativa utiliza a plataforma Wiki, na qual são descritos os principais fluxos dos processos trabalhistas, com a descrição de suas tarefas, os movimentos do e-Gestão (principal sistema de gerenciamento de informações judiciárias da Justiça do Trabalho) e modelos de minutas de despachos e de outros expedientes.

Assim, após a criação desse inventário de tarefas, procedimentos, tempos, pesos, responsabilidade, não conformidade e formas de controle, aliada a adição dos fatores extraprocessuais, da jornada de trabalho, dos dias úteis, do número de colaboradores da equipe de execução, será possível criar uma meta da produtividade da mão de obra, bem como acompanhar seu desenvolvimento.

Essa forma sugerida, faz parte da Administração Clássica, e se enquadra na combinação dos estudos de Frederick Winslow Taylor e do casal Gilbreth, a qual formou o conceito de estudo de tempos e movimentos:

A aplicação dos conceitos de tempos e movimentos ocorre em quatro etapas: a pesquisa e definição do melhor método de trabalho; a padronização do melhor método encontrado; a determinação do tempo padrão de trabalho e o treinamento dos colaboradores. (TÁLAMO, 2016, p. 14). 
Tálamo (2016) sugere que a pesquisa e definição do melhor método de trabalho seja um ciclo permanente de evolução, uma vez que, analogamente, o Direito, os equipamentos, programas e mão de obra, são dinâmicos e mudam com o tempo.

Ele apresenta uma subdivisão dessa primeira etapa em outros cinco itens: a identificação da necessidade; análise do processo a ser implantado; pesquisa de alternativas; análise das alternativas e definição do método adequado.

Outro ponto de destaque é o Controle Estatístico de Processo (CEP), apresentado por Ritzman (2004), como uma ferramenta de análise de dados, com técnicas estatísticas para verificar a conformidade de determinado resultado e também os impactos de eventual mudança no processo.

Essa ferramenta utiliza-se de gráficos de controle para detectar falhas ou mudança no processo, e ajudam na tomada de decisões do gestor sobre eventuais correções. Para ele, as variações dos resultados basicamente são de duas categorias, causas usuais ou atribuíveis (especiais). As primeiras são fontes de variação puramente aleatórias e não identificáveis que são inevitáveis no processo atual. E as segundas incluem quaisquer fatores que podem ser identificados e eliminados.

Outrossim, para Ritzman (2004), produtividade é igual aos produtos e serviços, divididos pelos insumos. E ainda, segundo ele, existem várias medidas de produtividade possíveis, as quais são meras aproximações.

Podemos citar dois exemplos dessas medidas, dados por Ritzman (2004), a produtividade da mão de obra, a qual mede o número de processos judiciais movimentados no dia por um servidor; e a produtividade geral, que mede mais de um recurso produtivo.

Baseado nisso, Ritzman (2004) considera aumento de produtividade, a mesma produção, se houver uma redução de insumos; ou a mesma produção e insumos, se houver melhor qualidade dos produtos. 
E considerando que, como regra, a execução realiza-se no interesse do credor, nos termos do artigo 797 da Lei no 13.105, de 16 de Março de 2015, Código de Processo Civil - CPC, o gestor deverá basear sua estratégia sob esta ótica. Utilizaremos neste estudo três prioridades competitivas apresentadas por esse autor: qualidade, tempo e flexibilidade.

Em relação à qualidade, ela é apresentada por Ritzman (2004) como um fator do produto ou serviço, e pode ser dividida em projeto de alto desempenho e qualidade consistente, a qualidade deve ser definida pelo cliente.

O projeto de alto desempenho pode incluir características superiores, tolerâncias menores, nível de ajuda, cortesia e disponibilidade dos empregados que prestam o atendimento e segurança dos produtos ou serviços. Ele determina o nível de operações necessário para a fabricação de um produto ou prestação de um serviço.

A qualidade consistente avalia a frequência com que o produto ou serviço atende às especificações do projeto. Para concorrer com base nessa prioridade, o gestor deve projetar e monitorar operações para reduzir erros. (RITZMAN, 2004, p.14-15).

Também importante, é a prioridade competitiva tempo, que pode ser subdividida em: prazo de entrega rápido (tempo de espera) e entrega pontual. Para esse autor:

O prazo de entrega rápido é o tempo decorrido entre o recebimento do pedido de um cliente e seu atendimento. Já a entrega pontual avalia com qual frequência as promessas de prazo de entrega são cumpridas. (RITZMAN, 2004, p.16).

E por fim, a prioridade competitiva flexibilidade, que segundo Ritzman (2004), permite uma resposta rápida e eficiente a diferentes necessidades, e subdivide-se em customização e flexibilidade de volume:

A customização é a habilidade para atender a necessidade específica de cada cliente e a flexibilidade de volume diz respeito à competência de adaptação à variação da demanda. (RITZMAN, 2004, p.16).

Outro alerta de Ritzman (2004) é sobre a necessidade de seleção de alguma prioridade competitiva em detrimento de outra, e também sobre a exigência credenciadora do serviço, que é o fato de que em determinadas jurisdições, uma 
prioridade competitiva pode tornar-se obrigatória, para a permanência do gestor no cargo.

E por fim, Ritzman (2004) conclui que, as prioridades competitivas fornecem a base para o projeto de processos. E apresenta três estratégias para os processos orientados a serviços: serviços padronizados, de atendimento por encomenda e serviços customizados:

A estratégia de serviços padronizados é para serviços com pouca variedade em volumes elevados e tem como prioridades competitivas: qualidade consistente e entrega pontual.

Já a estratégia de atendimento por encomenda é para processos que produzem um conjunto de serviços para atendimento das necessidades específicas do cliente e tem como prioridades competitivas: customização e entrega rápida.

E a última estratégia é a de serviços customizados, que é para fornecimento de serviços individualizados e tem como prioridades competitivas: projeto de alto desempenho e customização. (RITZMAN, 2004, p.17-18).

Essa interação do processo judicial com o processo industrial e a utilização de suas ferramentas àquele processo, deve ser cuidadosamente trabalhada, para que haja uma positiva transformação para os trabalhadores do Judiciário e também para os jurisdicionados.

Acreditamos que com cautela e adaptação dessas ferramentas à gestão da fase de execução, e em especial para os atos de mero expediente, que são aqueles operacionalizados por servidores públicos auxiliares da Justiça, é possível um controle de produtividade mais assertivo.

Porque esses atos possuem em grande parte previsibilidade de causa e efeito e minutas de decisão padronizadas, que no caso concreto exigiriam do servidor, o acerto no modelo de minuta a ser utilizado, de pequenos ajustes gramaticais em seu conteúdo e complementação de alguns dados. 
Dessarte, esse estudo busca verificar como as variáveis qualidade, tempo e flexibilidade influenciam na produtividade da fase de execução trabalhista, como cada estratégia competitiva influencia na produtividade, como calcular a produtividade geral da fase de execução, e como medir a produtividade da fase de execução?

\section{MÉTODO}

Por todo o exposto, escolhemos como objeto de pesquisa: o controle de produtividade na fase de execução trabalhista, e para seu estudo separamos duas hipóteses para utilização desse controle pelos gestores: produtividade da mão de obra e produtividade geral, além de quatro variáveis que podem influenciar nesse resultado: número de processos movimentados por dia, qualidade, tempo e flexibilidade.

Trata-se de um trabalho científico original de pesquisa aplicada, por meio do procedimento descritivo nas formas de estudos descritivos e de pesquisa de opinião. E em relação à amostragem, utilizou-se nos estudos descritivos as tarefas da fase de execução do Fluxo Nacional da Justiça do Trabalho - FNJT a seguir: "realizar Bacenjud do devedor"; "realizar pesquisa patrimonial básica" e "providenciar hasta pública", como pontos de referência dentro da execução trabalhista.

E a pesquisa de opinião, mediante o uso da técnica de formulário, pela ferramenta do Google Formulários, focou-se na prioridade competitiva tempo e contou com 50 participantes, os quais em sua maioria apresentaram o seguinte perfil: 48\% possuíam idade acima de 25 anos até 40 anos; $60 \%$ possuíam nível de escolaridade de pósgraduação ou acima; $54 \%$ atuavam profissionalmente como empregados da iniciativa privada; 52\% tinham tempo de experiência profissional acima de 10 anos até 20 anos; e 38\% já participaram de algum processo trabalhista.

E ainda, foi realizado um estudo bibliográfico, para embasamento teórico de tópicos como o serviço público, teletrabalho, produtividade presencial e em teletrabalho, controle de produtividade de trabalho, com a leitura dos livros descritos na bibliografia, do trabalho acadêmico de especialista na área trabalhista e da legislação correspondente. 


\section{RESULTADOS E DISCUSSÃO}

Com o intuito de encontrar as melhores práticas para o controle de produtividade na fase de execução, escolheu-se como amostra da análise descritiva três tarefas do Fluxo Nacional da Justiça do Trabalho - FNJT, consideradas chaves para toda a fase de execução. E em ordem processual cronológica, são elas: "realizar Bacenjud do devedor"; "realizar pesquisa patrimonial básica" e "providenciar hasta pública".

Essa escolha diminui a complexidade da fase de execução para facilitar o entendimento do estudo, mantendo sua essência, que é a de expropriação de bens do devedor para satisfação de um crédito. Outras tarefas e subtarefas relacionadas a essas três foram abordadas indiretamente, por meio de alguns de seus produtos ("outputs"). Sem prejudicar a possibilidade de uma maior individualização no planejamento operacional futuramente.

A descrição da operação de cada uma dessas tarefas dada pelo FNJT é "Realizar Bacenjud do devedor": realizar constrição de numerário, em conta bancária, por meio do sistema Bacenjud. "Realizar pesquisa patrimonial básica": expedir mandado de pesquisa patrimonial básica.

"Providenciar hasta pública": realizar ato saneador de irregularidades a permitir a alienação dos bens, tais como intimação de cônjuges ou coproprietários, credor hipotecário, necessidade de remoção do bem, etc.

E a partir das descrições dessas atividades, podemos buscar entender quais são as causas de variações dos resultados produtivos na fase de execução trabalhista. $E$ focaremos nas variáveis que impactam na produtividade e possam ser identificadas e eliminadas, como o número de processos movimentados por dia, qualidade, tempo e flexibilidade.

Nessa lógica, uma questão importante é a análise do produto de cada etapa ("outputs"), que pode ser quantitativa ou qualitativa. Assim, há produtos da fase de execução que podem ser computados na produtividade da mão de obra, os quais 
denominaremos como produtos contáveis, são eles: as minutas de decisão (no sentido amplo) criadas pelo servidor; e o cumprimento de uma decisão já despachada pelo Magistrado que gere movimento suficiente para alterar a data de entrada do processo em determinada tarefa.

Mas há também produtos relacionados à determinada tarefa que não geram movimento processual, que chamaremos de produtos não contáveis, e que por isso não podem ser acrescidos à produtividade da mão de obra, e são de dois tipos, o primeiro tipo é o produto do cumprimento de uma decisão judicial que não altera a data de entrada na tarefa, são os produtos não contáveis judiciais; e o segundo tipo são produtos relacionados a questões "burocráticas" que não possuem determinação judicial, que chamaremos de produtos não contáveis burocráticos.

E para melhor entendimento, utilizaremos de exemplo os produtos ("outputs") relacionados à tarefa "realizar pesquisa patrimonial básica". Para essa tarefa há dois produtos contáveis: a criação da minuta de determinação da expedição do mandado e a própria expedição do mandado.

Perceba que é possível que um processo seja contabilizado duas vezes na produtividade por mão de obra para uma mesma tarefa, criando a impressão de alto desempenho produtivo ou mesmo permitindo que a produtividade seja computada ao servidor, mesmo que ele não tenha realizado o serviço completo.

A fim de se evitar esse tipo de situação, criou-se o conceito de trabalho concentrado, que tem a ideia de que o mesmo servidor que fez a minuta de decisão, fique responsável pelo cumprimento de suas determinações, após a assinatura da minuta pelo Magistrado, e assim, computando-se apenas um processo movimentado.

Ocorre que, os produtos não contáveis, podem consumir mais tempo de trabalho dos servidores do que os produtos contáveis, e para que possamos também medir a produtividade dos produtos não contáveis temos duas opções. A primeira é começarmos a contá-los, mas isso proporcionaria um resultado enganoso ao gestor, 
porque coloca os servidores em um ciclo vicioso na busca de tarefas inócuas e incentiva uma estrutura burocrática e ineficaz.

A segunda opção seria considerarmos os produtos não contáveis como produtos relacionados à qualidade. E como a qualidade do produto deve ser definida pelo cliente, conseguimos evitar esse ciclo se atendermos os critérios de qualidade definidos. E para isso, precisamos saber quem é o cliente imediato de cada tarefa, descoberto mediante análise da próxima tarefa do fluxo.

E no auxílio do controle de qualidade dos produtos, os checklists são muito úteis, e para ilustrar o raciocínio, preparamos itens de verificação de qualidade, que são representados pelos produtos não contáveis judiciais e burocráticos, para dois clientes-tarefa internos da fase de execução: "realizar pesquisa patrimonial básica" e "providenciar hasta pública".

Assim, o cliente "realizar pesquisa patrimonial básica", considera que o produto entregue a ele foi de qualidade se: realizada a pesquisa de outras ações trabalhistas na certidão eletrônica de ações trabalhistas - CEAT, se realizada a pesquisa de certidões de diligências em execução no EXE15, se reservado ou penhorado valores em outras varas, caso haja, se incluídos todos os sócios, seja por mera decisão, se empresário individual, seja por meio de abertura de Incidente de Desconsideração de Personalidade Jurídica, inclusive a modalidade Inversa, se não.

E mais, se reconhecido eventual grupo econômico, se realizada a reunião de execução, com a escolha de um processo piloto para seu prosseguimento, se realizadas as restrições dos executados no Banco Nacional de Devedores Trabalhistas - BNDT, no Serasajud e no Cadastro Nacional de Indisponibilidade de Bens - CNIB.

E a lista de produtos não contáveis continua, para haver um produto de qualidade, ele também terá que ter seu cadastro na planilha específica de processos pilotos, ser habilitado no cadastro de devedores trabalhistas no EXE15 e ter incluídos os valores 
executados de todos os processos reunidos no cadastro do processo piloto, via PJeCalc e sua exportação para esses autos.

Quanto ao cliente "providenciar hasta pública", embora parte da descrição de seu serviço seja realizar ato saneador, a palavra sanear, demonstra que há algo errado ou incompleto, assim é possível reprovar a qualidade do produto ("output") a ele fornecido.

E para evitar uma não conformidade, o fornecedor desse cliente deverá fazer um checklist que identifique a existência e o cumprimento dos produtos não contáveis, como o bem que deverá ir à hasta, o proprietário, se há cônjuge não executado, coproprietários não executados, credores hipotecários ou fiduciários, o ID. da penhora e da avaliação, porcentagem da penhora, decisão para penhora de percentual diferente do que o executado possui, depositário nomeado, o ID. da procuração dos advogados dos executados.

E mais, o ID. da ciência da penhora, avaliação e do encargo de depositário, o número da averbação da penhora na matrícula de imóvel, a existência de inquilino ou morador no imóvel que não faz parte do processo, comprovação de notificação da penhora e avaliação, a informação se houve reavaliação, o ID. da notificação da reavaliação.

E ainda, o ID. da notificação para audiência de tentativa de conciliação, o ID. da decisão de dispensa de audiência de tentativa de conciliação, o ID. da audiência de tentativa de conciliação, a existência ou não de Embargos de Terceiro - ET, o ID. da certidão de Trânsito em Julgado dos ET, o cadastro do bem e seu vínculo aos autos no EXE15. E somente após a constatação de todos esses itens, será possível a aprovação da qualidade do produto entregue ao cliente-tarefa "providenciar hasta pública".

Por outro lado, a variável tempo é inversamente proporcional a produtividade. Contudo, não há ociosidade de algum cliente interno (tarefa no fluxo processual) na fase de execução, que pudesse demandar de seu fornecedor agilidade na entrega de seu produto. Esse fato faz com que a prioridade competitiva tempo na fase de 
execução trabalhista deva ser analisada sob a ótica do cliente externo da Justiça do Trabalho, como os advogados, partes, peritos, leiloeiros e arrematantes.

E consequentemente, para o controle de produtividade do servidor, a variável tempo aplicar-se-á, principalmente, aos resultados dos estudos de tempos e movimentos de cada tarefa, possibilitando que o gestor apresente metas inteligentes (específicas, mensuráveis, atingíveis, relevantes e temporais); e na escolha da unidade de medida de produção, como exemplo, uma produtividade de 8 processos por dia, 40 processos por semana ou 240 processos por mês.

Mas como estratégia de competitividade, a variável tempo tem outra abordagem nessa fase processual, que também impacta diretamente na forma de trabalho adotada pela equipe. Como exemplo, temos que para sua subdivisão entrega pontual é possível aplicar-se o conceito criado de "Processo do Dia", que é uma promessa do Judiciário, de que todos os processos, cujo prosseguimento dependa dele, serão movimentados dentro de um prazo predeterminado, contado a partir da entrada dos autos processuais em determinada tarefa.

Com o intuito de verificar a opinião dos clientes externos da Justiça, foi realizada uma pesquisa de opinião, na qual $42 \%$ dos entrevistados consideram o prazo de até 30 dias para análise de uma petição razoável, 36\% até 70 dias, 22\% até 120 dias e $0 \%$ até 180 dias.

E $42 \%$ deles consideram a demora judicial de até 70 dias razoável, sob a ótica do credor, para que haja movimento de um processo que dependa da Justiça, $28 \%$ até 120 dias, 26\% até 30 dias e 4\% até 180 dias.

Outra variável que influencia na produção é a flexibilidade, pois ela permite que seja dada uma resposta rápida e eficiente a diferentes clientes. E quando aqui citamos flexibilidade, referimo-nos a uma ferramenta de gestão estratégica, e não de competência interpessoal. 
Assim, sob essa visão, a flexibilidade será abordada como opções de estratégia dos gestores para influenciar na produtividade. Ela é subdividida em customização e flexibilidade de volume.

A customização, que é a capacidade de atender a necessidade de cada cliente, relaciona-se com a margem de discricionariedade dada pelos Magistrados e Gestores aos servidores. Ela facilita o aumento da produtividade da mão de obra e da diminuição do tempo de entrega. Todavia, pode prejudicar a qualidade do produto.

E embora na fase de execução seja inviável a criação de modelos de minuta de decisão para todas as opções, não é possível a adoção da flexibilidade para que os servidores alterem substancialmente a minuta de decisão. Porque a jurisdição, ou seja, o poder de dizer o Direito ao caso concreto, pertence aos Magistrados e não aos servidores.

Portanto, a customização na Justiça fica prejudicada, uma vez que há um gargalo na prestação de serviços jurisdicionais, que é o número de Juízes que o Estado possui, frente ao número de processos judiciais. Contudo, esse problema pode ser diminuído, se houver a criação de um canal eletrônico de feedback, direto com os magistrados, com respostas rápidas, e que forme uma base de dados da Vara, de fácil acesso, visualização e busca por tema, por empresa e por fase, para casos atípicos.

E em relação à subdivisão flexibilidade de volume, que diz respeito à competência de adaptação à variação da demanda, sua influência na execução será devida a estratégias adotadas pelos Gestores. Considerando que, grande parte da execução vem da fase de conhecimento e não diretamente de um título executivo extrajudicial, a maior possibilidade de um aumento substancial de sua demanda, em curto espaço de tempo, viria de mutirões de trabalho ou de forças tarefas externas.

A partir disso, podemos concluir que, para o cálculo da produtividade geral na fase da execução trabalhista, poderemos utilizar dessas quatro variáveis aqui estudadas: produtividade da mão de obra, qualidade, tempo e flexibilidade. 
E para a contabilização da produtividade da mão de obra, considerar-se-á sua abrangência restrita aos produtos contáveis em regime de trabalho concentrado, e será medida em número de processos movimentados pela unidade de tempo escolhida.

Para a variável qualidade na execução trabalhista, temos que ela está relacionada ao cumprimento de tarefas de um processo judicial que não são computadas na produtividade da mão de obra. Embora, seu cumprimento pelos servidores seja obrigatório.

Essas tarefas devem estar descritas ou no Fluxo Nacional da Justiça do Trabalho, em um Manual de Estudo dos Tempos e Movimentos dos procedimentos locais ou em determinações judiciais ou normativas.

A qualidade será medida pelo cliente tarefa seguinte ao do fornecedor tarefa, por meio de um checklist específico para cada uma delas. E em caso de não conformidade, o processo será devolvido ao fornecedor tarefa para retrabalho. E esse processo não poderá ser computado novamente na produtividade da mão de obra, quando do seu retrabalho.

E sobre a medida tempo, vimos que para o controle de produtividade do servidor, a prioridade competitiva tempo não é relevante, porque o tempo de cada tarefa deve ser cientificamente trabalhado pelos gestores no manual de tempos e movimentos das tarefas da fase de execução e dinamicamente aperfeiçoado.

Bem como, pelo treinamento da equipe para uniformização dos procedimentos e consequentemente com ganho da produtividade. E se não houver alteração de um procedimento, a equipe com o tempo alcançará um limite de performance e a produtividade, se nada mais houver, manter-se-á estável.

Contudo, a prioridade competitiva tempo interessa para a estratégia do gestor, porque se é o gestor quem designa a tarefa a ser executada pelo servidor, o resultado dessa escolha não poderá ser creditado ou debitado do subordinado. 
Por exemplo, se o gestor optar por uma estratégia de tempo, que prevê uma análise de todas as petições dentro de 30 dias contados de seu protocolo, a maioria dos processos que serão movimentados, serão os de advogados das partes que peticionarem mais.

Em contrapartida, se optar por movimentar todos os processos que dependam da Justiça para ser movimentado dentro de 30 dias, ele não poderá passar petições de processos que estejam fora desse prazo para que o servidor encaminhe a conclusão, sob pena de prejudicar a estratégia posta.

E por fim, a prioridade competitiva flexibilidade, subdividida em customização e flexibilidade de volume traz diferentes impactos na produtividade. Primeiro a customização, em casos que fogem às minutas padronizadas ou decisões pretéritas, que exijam uma mudança jurídica substancial na ideia da minuta ou a criação de um novo modelo de minuta, como os servidores não têm Jurisdição Constitucional, não podem assinar as minutas por eles preparadas. E por dedução lógica, seu conteúdo jurídico deve ser emanado dos Magistrados.

Com isso, a falta de flexibilidade para alteração de uma minuta de decisão do servidor, por ser da natureza desse cargo, remeterá a duas situações, que dependerá da escolha do Magistrado, que podem influenciar ou não no número de minutas produzidas pelo servidor, a depender de quantos casos concretos ele pegar que fujam do padrão.

A primeira situação, que não haverá necessidade de qualquer intervenção no resultado da produtividade do servidor, será quando o servidor verificar que aquele caso precisa de uma customização além da padronizada e imediatamente ele repassar o processo aos Gestores e Magistrados.

Já esta segunda situação deverá ser considerada como fator de diminuição da produtividade, que é a conduta do servidor que ao constatar que aquele caso exija uma customização além da padronizada, ele ter a autorização de criar uma minuta 
para aquele caso concreto, mas não enviar para assinatura, e sim para estudo do caso concreto pelo Magistrado.

E pela subdivisão da flexibilidade de volume, como há um limite de produtividade por servidor, para se evitar eventual descontrole do cumprimento do prazo nos "processos do dia", o gestor deverá evitar fazer mutirão ou se utilizar de força-tarefa externa, e se o fizer, deverá preparar sua equipe para o enfrentamento desse aumento.

\section{CONSIDERAÇÕES FINAIS}

Dessa maneira, com as descrições e divisão dos procedimentos das tarefas apresentadas, é possível diminuir a complexidade da fase de execução como um todo. E com isso, aumentar a padronização e produtividade da mão de obra, aplicando-se os conceitos de tempos e movimentos para cada uma delas.

Note-se que de acordo com as descrições das tarefas, o gestor pode ser levado a escolher o controle de produtividade por mão de obra, como melhor forma de controlar a produtividade na fase de execução. Contudo, muito do tempo e esforços despendidos pelos servidores na fase de execução, são gastos com a qualidade do serviço e não com o cumprimenta dos produtos contáveis.

Por isso, a escolha da forma adequada de medir a produtividade na fase de execução trabalhista, dependerá da estratégia competitiva adotada pelos Magistrados e Gestores, porque na maioria dos casos, não é possível atingir os melhores índices em todas as variáveis relacionadas a ela.

$E$ as ferramentas aqui apresentadas auxiliam em um controle mais amplo e efetivo da produtividade, que podem ser usadas pelos superiores hierárquicos de maneira dinâmica, ou seja, poderá haver uma combinação de estratégias dentro de suas diferentes tarefas, ou mesmo como um todo, mas em diferentes cenários.

O importante, portanto, é que, a expectativa da produtividade seja compatível com a estratégia competitiva adotada. E seu controle histórico deve conter além da estratégia adotada naquele período, os resultados das outras variáveis que se 
relacionam com a produtividade, mesmo que não sejam considerados no cômputo da produtividade, para verificação do impacto nos resultados por mudanças na estratégia a longo prazo.

\section{REFERÊNCIAS BIBLIOGRÁFICAS}

BRASIL. Decreto-lei ํㅜ 5.452, de $1^{\circ}$ de Maio de 1943. In: PRESIDÊNCIA DA REPÚBLICA. Base de Dados do Planalto. 2020. Disponível em: $<$ http://www.planalto.gov.br/ccivil_03/decreto-lei/Del5452compilado.htm>. Acesso em: 23 jun. 2020.

BRASIL. Lei ㄲo 13.105, de 16 de Março de 2015. In: PRESIDÊNCIA DA REPÚBLICA. Base de Dados do Planalto. 2020. Disponível em: <http://www.planalto.gov.br/ccivil_03/_ato2015-2018/2015/lei//13105.htm>. Acesso em: 23 jun. 2020.

CASTRO, Ana Cristina de; CASTRO, Cláudia Osório de. Gestão pública contemporânea [livro eletrônico]; série Gestão Pública. 1a edição. Curitiba: InterSaberes, 2014.

CONGRESSO INTERNACIONAL DE DIREITO E CONTEMPORANEIDADE, 3.; CONGRESSO IBEROAMERICANO DE INVESTIGADORES E DOCENTES DE DIREITO E INFORMÁTICA, V., 2015, Santa Maria. Anais eletrônicos... Santa Maria: UFSM, 2015. Disponível em: <http://coral.ufsm.br/congressodireito/anais/2015/12.pdf>. Acesso em: 16 jun. 2020.

COVID-19: Produtividade. In: TRIBUNAL REGIONAL DO TRABALHO DA 15a REGIÃO. Relatório de Produtividade do TRT15. 2020. Disponível em: $<$ https://trt15.jus.br/transparencia/estatisticas-processuais/covid-19produtividade>. Acesso em: 23 jun. 2020.

FLUXO Nacional da Justiça do Trabalho. In: JUSTIÇA DO TRABALHO. WikiVT. 2019. Disponível em: <https://fluxonacional.jt.jus.br/>. Acesso em: 20 jun. 2020. 
RITZMAN, Larry P.; KRAJEWSKI, Lee J.. Administração da Produção e Operações; tradução Roberto Galman. 1a edição. São Paulo: Prentice Hall, 2004.

TÁLAMO, J. Roberto. Engenharia de métodos. o estudo de tempos e movimentos [livro eletrônico]; série Administração da Produção. 1a edição. Curitiba: InterSaberes, 2016.

Enviado: Julho, 2020.

Aprovado: Dezembro, 2020. 